\title{
A Comprehensive Physical, Spectroscopic, and Thermal Characterization of Withania somnifera (Ashwagandha) Root Extract Treated with the Energy of Consciousness (The Trivedi Effect ${ }^{\circledR}$ )
}

\author{
Mahendra Kumar Trivedi ${ }^{1}$, Alice Branton ${ }^{1}$, Dahryn Trivedi ${ }^{1}$, Gopal Nayak ${ }^{1}$, \\ Cathryn Dawn Nykvist ${ }^{1}$, Celine Lavelle ${ }^{1}$, Daniel Paul Przybylski ${ }^{1}$, Dianne Heather Vincent ${ }^{1}$, \\ Dorothy Felger ${ }^{1}$, Douglas Jay Konersman ${ }^{1}$, Elizabeth Ann Feeney ${ }^{1}$, Jay Anthony Prague ${ }^{1}$, \\ Joanne Lydia Starodub ${ }^{1}$, Karan Rasdan ${ }^{1}$, Karen Mie Strassman ${ }^{1}$, Leonid Soboleff ${ }^{1}$, \\ Maire Anne Mayne ${ }^{1}$, Mary M. Keesee ${ }^{1}$, Padmanabha Narayana Pillai ${ }^{1}$, Pamela Clarkson Ansley ${ }^{1}$, \\ Ronald David Schmitz ${ }^{1}$, Sharyn Marie Sodomora ${ }^{1}$, Kalyan Kumar Sethi ${ }^{2}$, Parthasarathi Panda ${ }^{2}$, \\ Snehasis Jana ${ }^{2, *}$ \\ ${ }^{1}$ Trivedi Global, Inc., Henderson, Nevada, USA \\ ${ }^{2}$ Trivedi Science Research Laboratory Pvt. Ltd., Bhopal, Madhya Pradesh, India
}

Email address:

publication@trivedieffect.com (S. Jana)

${ }^{*}$ Corresponding author

To cite this article:

Mahendra Kumar Trivedi, Alice Branton, Dahryn Trivedi, Gopal Nayak, Cathryn Dawn Nykvist, Celine Lavelle, Daniel Paul Przybylski, Dianne Heather Vincent, Dorothy Felger, Douglas Jay Konersman, Elizabeth Ann Feeney, Jay Anthony Prague, Joanne Lydia Starodub, Karan Rasdan, Karen Mie Strassman, Leonid Soboleff, Maire Anne Mayne, Mary M. Keesee, Padmanabha Narayana Pillai, Pamela Clarkson Ansley, Ronald David Schmitz, Sharyn Marie Sodomora, Kalyan Kumar Sethi, Parthasarathi Panda, Snehasis Jana. A Comprehensive Physical, Spectroscopic, and Thermal Characterization of Withania somnifera (Ashwagandha) Root Extract Treated with the Energy of Consciousness (The Trivedi Effect ${ }^{\circledR}$ ). International Journal of Biomedical Materials Research. Vol. 5, No. 1, 2017, pp. 5-14. doi: 10.11648/j.ijbmr.20170501.12

Received: February 6, 2017; Accepted: February 18, 2017; Published: March 7, 2017

\begin{abstract}
Withania somnifera (Ashwagandha) root extract possesses a broad range of pharmacological activities. The aim of current study was to explore the impact of The Trivedi Effect ${ }^{\circledR}$ - Energy of Consciousness Healing Treatment (Biofield Energy Healing Treatment) on the physical, spectroscopic, and thermal properties of ashwagandha root extract using PXRD, PSD, FTIR, UV-vis spectroscopy, TGA, and DSC analysis. Ashwagandha root extract was divided into two parts. One part was denoted as the control, while the other part was defined as The Trivedi Effect ${ }^{\circledR}$ - Biofield Energy Treated sample, which received The Trivedi Effect ${ }^{\mathbb{B}}$ Treatment remotely from eighteen renowned Biofield Energy Healers. The PXRD analysis exhibited that both the control and The Trivedi Effect ${ }^{\circledR}$ - Biofield Energy Treated samples were amorphous in nature. The particle size values at $d_{10}$ and $d_{50}$ of the treated sample were decreased by $4.66 \%$ and $6.02 \%$ and at $d_{90}$ slightly increased by $0.99 \%$ compared with the control sample. The average surface area of the treated $\left(0.130 \mathrm{~m}^{2} / \mathrm{g}\right)$ sample was increased by $4.84 \%$ compared with the control $\left(0.124 \mathrm{~m}^{2} / \mathrm{g}\right)$ sample. The FT-IR results suggested that the force constant of O-H (stretching), and $\mathrm{C}-\mathrm{O}$ (stretching) functional groups of the treated sample were reduced compared with the control sample. The UV-vis analysis revealed that the wavelength for the maximum absorbance of the control and treated samples were at $205.4 \mathrm{~nm}$ and $205.6 \mathrm{~nm}$, respectively. The TGA thermograms exhibited three steps of the degradation process, and the total weight loss of the treated (86.45\%) sample was increased by $1.44 \%$ compared with the control (85.22\%) sample. The DSC analysis revealed that melting point of the treated $\left(201.67^{\circ} \mathrm{C}\right)$ sample was reduced by $0.87 \%$ compared with the control $\left(203.43^{\circ} \mathrm{C}\right)$ sample. The latent heat of fusion of the treated $(6.77 \mathrm{~J} / \mathrm{g})$ sample was significantly decreased by $21.82 \%$ compared to the control $(8.67 \mathrm{~J} / \mathrm{g}) \mathrm{sample}$. Hence, the treated sample would be more advantageous for the better therapeutic responses compared to the control sample. These findings suggest that The Trivedi Effect ${ }^{\circledR}$ - Energy of Consciousness Healing Treatment might have the astounding capacity to
\end{abstract}


enhance the solubility, dissolution, absorption, and bioavailability of ashwagandha root extract in various forms of pharmaceutical/nutraceutical formulations by modifying its particle size and surface area. Thus, The Trivedi Effect ${ }^{\circledR}$ - Energy of Consciousness Healing Treated ashwagandha root extract might provide better therapeutic response against inflammatory diseases, immunological disorders, stress, arthritis, cancer, diabetes, sexual disorders, aging and other chronic infections.

Keywords: Withania somnifera, Biofield Energy Healing Treatment, Biofield Energy Healers, Consciousness Energy Healing Treatment, The Trivedi Effect ${ }^{\circledR}$, PXRD, Particle Size, TGA, DSC

\section{Introduction}

The importance of the herbal medicines in the prevention and treatment of the various diseases has been increased dayby-day throughout the world due to its impressive therapeutic effects and fewer side effects compared to the modern medicines [1]. The roots of Withania somnifera ( $W$. somnifera) (L.) Dunal (Family- Solanaceae) - a vital Rasayana herb is traditionally known as 'Ashwagandha' or winter cherry. In Ayurveda, it is called as 'Indian ginseng'. Ashwagandha is widely used in the most of the Indian herbal drugs and nutraceuticals for the treatment of various diseases include nervous and sexual disorders, infectious diseases, diabetes, cancer, ulcer, immunological disorders, stress, arthritis, etc. From the ancient time, it is used as a tonic to arrest the ageing process, rejuvenate the body and boost the defence against infectious disorders and also promote the longevity [2-11]. Ashwagandha root extract contains a wide array of nutrients and phytochemicals. Hence, it is used as a dietary supplement for the health restoration [3]. The major active phytoconstituents of ashwagandha root extract are highly oxygenated withanolides. Withanolides have C28 steroidal nucleus with C9 side chain, having a six membered lactone ring (Figure 1). The oxidation at various sites of the skeleton is responsible for the structural deviations in different classes of withanolides [11-14].

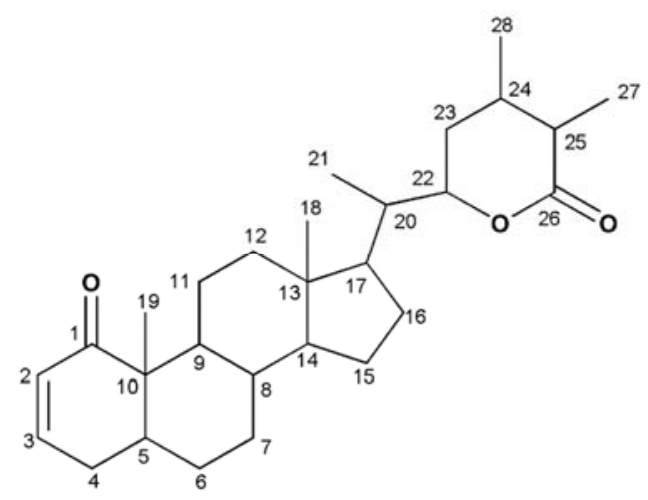

Figure 1. The basic skeleton of withanolide.

Literatures reported that withanolides such as withaferin A, withanolide $\mathrm{D}$, withanolide $\mathrm{E}$, etc. possesses various pharmacological activities include antioxidant, anticancer, immunomodulating, neuroprotective, antiepileptic, antibacterial, adaptogenic, spermatogenic, antidepressant, antianxiety, hepatoprotective, anti-inflammatory, antiarthritic, antimicrobial, hypoglycemic, hypolipidemic, aphrodisiac, antiulcer, radiosensitizing, etc. [11, 14-19]. Therefore, a new proprietary herbomineral formulation was formulated that consisted of the herbal product like ashwagandha root extract along with minerals such as zinc, magnesium, and selenium. This herbomineral formulation is designed as nutraceutical supplement and can be used for the prevention and treatment of various human disorders.

Every living organism preserves some kind of unique quality, an élan vital or vital force, which contributes the 'life'. From the ancient-time, this living force is known as Prana by the Hindus, $q i$ or chi by the Chinese, and $k i$ by the Japanese and is usually believed to create the source of life that is related with soul, spirit, and mind. Now-a-days, this hypothetical vital force is considered as the Bioenergetics Field. This energy field is a dynamic electromagnetic field existing surround of the human body. The Biofield Energy is infinite and paradimensional. It can freely flow between the human and the environment that leads to the continuous movement or matter of energy [20,21]. Thus, the human can harness energy from the earth, the "universal energy field" and transmit it to any living or nonliving object (s) around the globe. The objects always receive the energy and respond in a useful way. This process is known as Biofield Energy Healing Treatment [22, 23]. Biofield (Putative Energy Fields) based Energy Therapies are used worldwide to promote health and healing [24]. The National Center of Complementary and Integrative Health (NCCIH) has been recognized and accepted Biofield Energy Healing as a Complementary and Alternative Medicine (CAM) health care approach in addition to other therapies, medicines and practices such as natural products, deep breathing, yoga, Tai Chi, Qi Gong, chiropractic/osteopathic manipulation, meditation, massage, special diets, homeopathy, progressive relaxation, guided imagery, acupressure, acupuncture, relaxation techniques, hypnotherapy, healing touch, movement therapy, pilates, rolfing structural integration, mindfulness, Ayurvedic medicine, traditional Chinese herbs and medicines, naturopathy, essential oils, aromatherapy, Reiki, cranial sacral therapy and applied prayer (as is common in all religions, like Christianity, Hinduism, Buddhism and Judaism) [25]. The Biofield Energy Treatment (The Trivedi Effect ${ }^{\circledR}$ ) has been extensively studied with significant outcomes in many scientific fields such as cancer research [26], altered antimicrobial sensitivity of pathogenic microbes in microbiology [27-29], biotechnology [30, 31], genetics [32, 33], changing the structure of the atom in relation to the various metals, ceramics, polymers and chemicals materials science [34-36], altered physical and 
chemical properties of pharmaceuticals [37, 38], nutraceuticals [39, 40], organic compounds [41-43], and improved overall growth and yield of plants in agricultural science $[44,45]$. Herbal extracts and herbal drugs despite of their outstanding in vitro results exhibited poor or negligible in vivo activity, because of their reduced lipid solubility or improper molecular size, causing deprived absorption and thus poor bioavailability [1]. According to the recent study on the bioavailability of major withanolides of $W$. somnifera, Devkar et al. demonstrated that the nonpolar and low molecular weight withanolides were highly permeable, whereas the high glycosylated and polar withanolides displayed low permeability in their in vitro absorption model system [46]. As ashwagandha root extract has the outstanding nutritional and medicinal values, researchers are still working on to find out an optimal dosage range for reproducing the desired effects in human as well as to determine the safe, non-toxic, and effective dosage form [7]. The physicochemical properties such as particle size, crystalline structure, crystallite size, surface area, etc. and thermal properties of a drug have a vital role in bioavailability as well as the stability of the drug during processing, formulation, storage, and packaging [47, 48]. Biofield Energy Treatment (The Trivedi Effect ${ }^{\mathbb{B}}$ ) has been reported to change the particle size, specific surface area, crystalline, chemical and thermal behaviour of an atom/ion through the possible mediation of neutrinos [49]. By considering all these aspects, the objective of the current study was to examine whether the Biofield Energy Treatment can change the physical, structural, and thermal properties in such a way that might be assisting in the improvement of the solubility, absorption and also help in designing of any suitable pharmaceutical formulation. The physical, spectroscopic, and thermal properties of both the control and Biofield Energy Treated ashwagandha root extracts were evaluated using various analytical techniques include Fourier transform infrared (FT-IR) spectrometry, ultraviolet-visible (UV-vis) spectroscopy, powder X-ray diffraction (PXRD), particle size distribution analysis (PSD), thermogravimetric analysis (TGA), and differential scanning calorimetry (DSC).

\section{Materials and Methods}

\subsection{Chemicals and Reagents}

Withania somnifera (ashwagandha) hydroalcoholic root extract was purchased from Sanat Product Ltd, India. All the other chemicals used in this experiment were analytical grade procured from the local vendors.

\subsection{Energy of Consciousness Healing Treatment Strategy}

Ashwagandha root extract powder was one of the components of the new proprietary herbomineral formulation, developed by our research team, and it was used per se as the test compound for the current study. The test compound was divided into two parts, one part of the test compound was treated with The Trivedi Effect ${ }^{\circledR}$ - Energy of Consciousness Healing Treatment by renowned Biofield Energy Healers and defined as The Trivedi Effect $^{\mathbb{B}}$ sample, while the second part of the test compound did not receive any sort of treatment and defined as untreated or control ashwagandha root extract sample. The group of eighteen Biofield Energy Healers who participated in this study performed The Trivedi Effect ${ }^{\circledR}$ - Energy of Consciousness Healing Treatment remotely to the test compound. Eleven of the Biofield Energy Healers were located in the U. S. A., four in Canada, one in Ireland, one in the United Kingdom, and one in Russia performed The Trivedi Effect ${ }^{\mathbb{B}}$ on the test compound that was located in the research laboratory of GVK Biosciences Pvt. Ltd., Hyderabad, India. This Biofield Energy Treatment was provided for 5 minutes through Healer's Unique Energy Transmission process remotely to the test compound under the laboratory conditions. None of the Biofield Energy Healers in this study visited the laboratory in person, nor had any contact with the compounds. Similarly, the control compound was subjected to "sham" healers for 5 minutes, under the same laboratory conditions. The sham healer did not have any knowledge about The Trivedi Effect ${ }^{\circledR}$ - Biofield Energy Treatment. After that, the treated and untreated samples were kept in similar sealed conditions and were characterized thoroughly by PXRD, PSD, FT-IR, UV-visible spectroscopy, TGA, and DSC analysis.

\subsection{Characterization}

\subsubsection{Powder X-Ray Diffraction (PXRD) Analysis}

The PXRD analysis was accomplished on PANalytical X'pert Pro powder X-ray diffractometer system. The X-ray of wavelength $1.54056 \AA$ was used. The data was collected in the

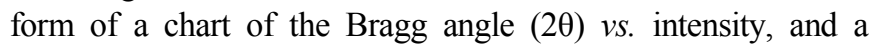
detailed table containing information on peak intensity counts, $\mathrm{d}$ value $(\AA)$, relative intensity (\%), full width half maximum (FWHM) $\left(\theta^{\circ}\right)$. From the XRD results, the crystallite size $(\mathrm{G})$ was calculated using X'pert data collector and X'pert high score plus processing software. A total of $500.19 \mathrm{mg}$ of control and $500.23 \mathrm{mg}$ of the treated samples individually used for the analysis and prepared by back loading technique using the sample preparation kit. The sample was spread on the holder ring in sufficient quantity to fill the ring cavity. It was then pressed down using powder press block and scrap the powder that was in surplus using a glass slide to get densely packed specimen. Consequently, the bottom plate was placed onto the holder ring and clamp in position. The sample holder was then removed from the sample preparation table by turning it upside down. A smooth surface of the sample was obtained to ensure the optimum results.

\subsubsection{Particle Size Distribution (PSD) Analysis}

The average particle size and particle size distribution were analyzed using Malvern Mastersizer 2000, UK with a detection range between $0.01 \mu \mathrm{m}$ to $3000 \mu \mathrm{m}$. The sample unit was filled with the dispersant medium and operated the stirrer at $2500 \mathrm{rpm}$. Alignment of the optics was done and the background measurement was taken. After the background measurement, the sample was added in to the sample unit with constant monitoring the obscuration and 
stopped the addition of sample when the obscuration reached in between $15 \%$ to $20 \%$. When the obscuration was stable, the measurement was taken twice, and the average was taken of two measurements. The average histogram of the two measurements was recorded. Along with histogram, the data was presented in a table format which includes particle size $(\mu \mathrm{m})$. Also, the values at below $10 \%$ level $\left(\mathrm{d}_{10}\right)$, $50 \%$ level $\left(\mathrm{d}_{50}\right)$, and $90 \%$ level $\left(\mathrm{d}_{90}\right)$ were calculated from the histogram, and the calculations such as surface area $\left(\mathrm{m}^{2} / \mathrm{g}\right)$ were done by using software Mastersizer 2000. Percent change in particle size (d) for at below 10\% level $\left(\mathrm{d}_{10}\right), 50 \%$ level $\left(\mathrm{d}_{50}\right)$, and $90 \%$ level $\left(\mathrm{d}_{90}\right)$ was calculated using following equation 1 :

$$
\% \text { change in particle size }=\frac{\left[\mathrm{d}_{\text {Treated }}-\mathrm{d}_{\text {Control }}\right]}{\mathrm{d}_{\text {Control }}} \times 100
$$

Where, $\mathrm{d}_{\text {Control }}$ and $\mathrm{d}_{\text {Treated }}$ are the particle size $(\mu \mathrm{m})$ for at below $10 \%$ level $\left(\mathrm{d}_{10}\right), 50 \%$ level $\left(\mathrm{d}_{50}\right)$, and $90 \%$ level $\left(\mathrm{d}_{90}\right)$ of the control and treated samples, respectively.

Percent change in surface area (S) was calculated using following equation 2 :

$\%$ change in surface area $=\frac{\left[\mathrm{S}_{\text {Treated }}-\mathrm{S}_{\text {Control }}\right]}{\mathrm{S}_{\text {Control }}} \times 100$

Where, $S_{\text {Control }}$ and $S_{\text {Treated }}$ are the surface area of the control and treated samples, respectively.

\subsubsection{Fourier Transform Infrared (FT-IR) Spectroscopy}

FT-IR spectroscopy of ashwagandha root extract was performed on Spectrum two (Perkin Elmer, USA) Fourier transform infrared spectrometer with the frequency array of $400-4000 \mathrm{~cm}^{-1}$ by using pressed $\mathrm{KBr}$ disk technique.

\subsubsection{Ultra Violet-Visible Spectroscopy (UV-Vis) Analysis}

The UV-Vis spectral analysis was carried out using Shimadzu UV-2450 with UV Probe, Japan. The spectrum was recorded using $1 . \mathrm{cm}$ quartz cell that has a slit width of $1.0 \mathrm{~nm}$. The wavelength ranges chosen for recording the spectra was $190-800 \mathrm{~nm}$. The absorbance spectra (in the range of 0.2 to 0.9$)$ and the wavelength of maximum absorbance $\left(\lambda_{\max }\right)$ were recorded.

\subsubsection{Thermal Gravimetric Analysis (TGA)}

The TGA analysis was performed using Instrument TGA Q50 (TA Instruments, USA) at a heating rate of $10^{\circ} \mathrm{C} / \mathrm{min}$ from room temperature i.e. $30^{\circ} \mathrm{C}$ to $900^{\circ} \mathrm{C}$ under nitrogen atmosphere. A total of $11.86 \mathrm{mg}$ of sample was used for the analysis and was taken on the platinum pan. In TGA, the weight loss for each step was recorded in grams as well as in percent loss with respect to the initial weight. Also, the onset, endset, and peak temperature for each step were recorded in TGA. Percent change in weight loss (W) was calculated using following equation 3 :

$$
\% \text { change in weight loss }=\frac{\left[\mathrm{W}_{\text {Treated }}-\mathrm{W}_{\text {Control }}\right]}{\mathrm{w}_{\text {Control }}} \times 100
$$

Where, $\mathrm{W}_{\text {Control }}$ and $\mathrm{W}_{\text {Treated }}$ are the weight loss of the control and Biofield Energy Treated samples, respectively.

\subsubsection{Differential Scanning Calorimetry (DSC)}

Analysis was performed using the DSC Q20 (TA Instruments, USA) differential scanning calorimeter. A total of $8.10 \mathrm{mg}$ sample was weighed and sealed in aluminium pan and equilibrated at $25^{\circ} \mathrm{C}$ and heated up to $450^{\circ} \mathrm{C}$ at the heating rate of $10^{\circ} \mathrm{C} / \mathrm{min}$ under nitrogen gas as purge atmosphere with the flow rate of $50 \mathrm{~mL} / \mathrm{min}$. The value for onset, endset, peak temperature, peak height ( $\mathrm{mJ}$ or $\mathrm{mW}$ ), peak area, and change in heat $(\mathrm{J} / \mathrm{g})$ for each peak were recorded. Percent change in melting point $(\mathrm{T})$ was calculated using following equation 4 :

$$
\% \text { change in melting point }=\frac{\left[\mathrm{T}_{\text {Treated }}-\mathrm{T}_{\text {Control }}\right]}{\mathrm{T}_{\text {Control }}} \times 100
$$

Where, $\mathrm{T}_{\text {Control }}$ and $\mathrm{T}_{\text {Treated }}$ are the melting point of the control and treated samples, respectively.

Percent change in latent heat of fusion $(\Delta \mathrm{H})$ was calculated using following equation 5 :

$$
\% \text { change in Latent heat of fusion }=\frac{\left[\Delta \mathrm{H}_{\text {Treated }}-\Delta \mathrm{H}_{\text {Control }}\right]}{\Delta \mathrm{H}_{\text {Control }}} \times 100
$$

Where, $\Delta \mathrm{H}_{\text {Control }}$ and $\Delta \mathrm{H}_{\text {Treated }}$ are the latent heat of fusion of the control and treated samples, respectively.

\section{Results and Discussions}

\subsection{Powder X-ray Diffraction (PXRD) Analysis}

The powder X-ray diffraction study was conducted to explore the crystalline pattern of the control and treated samples of ashwagandha root extract (Figure 2). The PXRD diffractograms of the control and treated samples of ashwagandha did not contribute any diffraction peaks, indicated that both the samples were amorphous in nature. The X-rays of the amorphous compound scatter in many directions leading to a large bump distribute in a wide range

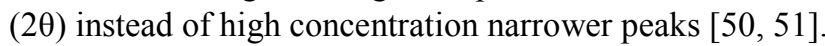
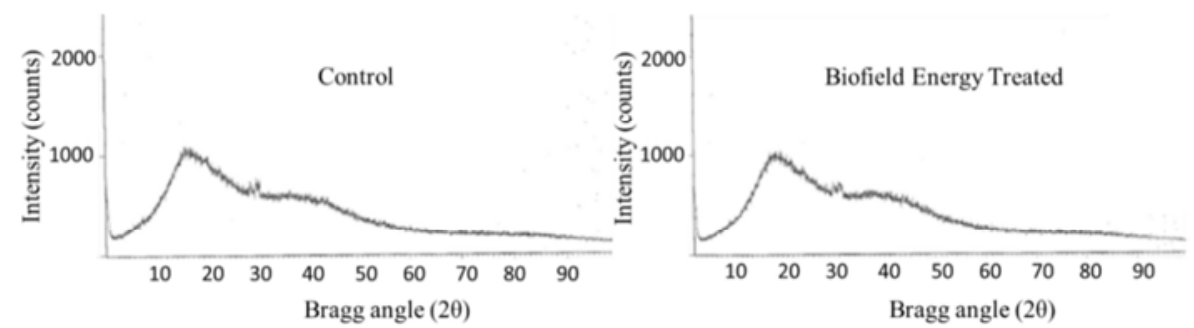

Figure 2. PXRD diffractograms of the control and Biofield Energy Treated W. somnifera (ashwagandha) root extract. 


\subsection{Particle Size Distribution (PSD) Analysis}

The particle size $\left(\mathrm{d}_{10}, \mathrm{~d}_{50}\right.$ and $\left.\mathrm{d}_{90}\right)$ of the control and treated samples were investigated, and the results are shown in Table 1. The particle size of the treated sample showed at $d_{10}$ and $\mathrm{d}_{50}$ was decreased by $4.66 \%$ and $6.02 \%$, respectively compared with the control sample. The particle size of the treated sample at $d_{90}$ was increased slightly by $0.99 \%$ compared with the control sample. The surface area of the treated sample $\left(0.130 \mathrm{~m}^{2} / \mathrm{g}\right)$ was increased by $4.84 \%$ compared with the control sample $\left(0.124 \mathrm{~m}^{2} / \mathrm{g}\right)$ (Table 1). The reduction in particle size leads to the increase in surface area in the treated sample. The results revealed that there might be an effect of the high energy milling induced by The Trivedi Effect ${ }^{\circledR}$ treatment to ashwagandha root extract. The decrease in the particle size and increase in the surface area has the significant influence on the increase in drug release, dissolution, absorption, drug action and dose uniformity of any substance in various drug delivery system [52].

Table 1. Particle size data $\left(d_{10,} d_{50}\right.$ and $\left.d_{90}\right)$ and surface area of the control and Biofield Energy Treated W. somnifera (ashwagandha) root extract.

\begin{tabular}{lllll}
\hline Test Item & $\mathbf{d}_{\mathbf{1 0}}(\boldsymbol{\mu m})$ & $\mathbf{d}_{\mathbf{5 0}}(\boldsymbol{\mu m})$ & $\mathbf{d}_{\mathbf{9 0}}(\boldsymbol{\mu m})$ & Surface $\operatorname{area}\left(\mathbf{m}^{\mathbf{2}} / \mathbf{g}\right)$ \\
\hline Control & 40.480 & 162.141 & 370.665 & 0.124 \\
Biofield Energy & 38.595 & 152.385 & 374.351 & 0.130 \\
Treated & -4.66 & -6.02 & 0.99 & 4.84 \\
\% change $^{\mathrm{a}}$ & &
\end{tabular}

${ }^{\text {a }}$ denotes the percentage change in the particle size data $\left(\mathrm{d}_{10}, \mathrm{~d}_{50}\right.$, and $\left.\mathrm{d}_{90}\right)$ and surface area of Biofield Energy Treated sample with respect to the control sample.

\subsection{Fourier Transform Infrared (FT-IR) Spectroscopy}

The FT-IR spectra displayed the prominent peaks correspond to the different functional groups of phytoconstituents present in both the control and treated ashwagandha root extract (Figure 3). The wavenumber of the absorbance $(v)$ of a diatomic can be calculated from the Hooke's law (Eq.6). The following equation gives the frequency of radiation (IR) that a molecule absorb and gives the frequency of vibration of the normal mode being excited by that radiation [53].

$$
v=\frac{1}{2 \pi c} \sqrt{\frac{f\left(m_{1}+m_{2}\right)}{m_{1} m_{2}}}
$$

Where, $\mathrm{v}=$ vibrational frequency $\left(\mathrm{cm}^{-1}\right), \mathrm{c}=$ the velocity of light $(\mathrm{cm} / \mathrm{s}), \mathrm{m}_{1}$ and $\mathrm{m}_{2}=$ the mass of atoms 1 and 2 , respectively in $\mathrm{g}, \mathrm{f}=$ the force constant of the bond (dyne/cm).

From the above equation 6 , it has been shown that if other factors remain constant, the vibrational frequency (wavenumber) is directly proportional to the force constant.

The FT-IR spectra (Figure 3) indicated the O-H stretching of the treated sample $\left(3367 \mathrm{~cm}^{-1}\right)$ was shifted downward compared with the control sample $\left(3392 \mathrm{~cm}^{-1}\right)$ (Table 2 , entry 1). The broad peak at $3600-3200 \mathrm{~cm}^{-1}$ may be due to the O-H functional group of the phytoconstituents present in the ashwagandha root extract $[10,53,54]$. Similarly, the C-O stretching of the treated sample $\left(1268 \mathrm{~cm}^{-1}\right)$ was shifted downward compared with the control sample $\left(1291 \mathrm{~cm}^{-1}\right)$. The results indicated that the force constant of the $\mathrm{O}-\mathrm{H}$ functional group of the treated sample was reduced compared with the control sample. The FT-IR exhibited similar aliphatic C-H stretching at 2927-2856 $\mathrm{cm}^{-1}$, and $\mathrm{C}=\mathrm{O}$ stretching at $1684 \mathrm{~cm}^{-1}$ for aldehyde/ketonic functional group in both the control and treated samples (Table 2, entry 2 and 3 ). The $\mathrm{C}=\mathrm{C}$ (aromatic bending), $\mathrm{C}-\mathrm{H}$ (aromatic and alkanes bending) and $\mathrm{C}-\mathrm{O}$ (alkoxy stretching) vibrations are similar in the treated sample compared with the control sample (Table 2, entry 7).

Table 2. FT-IR data of the control and Biofield Energy Treated W. somnifera (ashwagandha) root extracts.

\begin{tabular}{llll}
\hline \multirow{2}{*}{ Entry No. } & Mode of vibration & \multicolumn{2}{c}{ Characteristic absorption (s) of ashwagandha root extract (cm $\left.^{-1}\right)$} \\
\cline { 2 - 3 } & Control & \multicolumn{2}{c}{ Trivedi Effect ${ }^{\circledR}$ Treated } \\
\hline 1 & O-H stretching & 3392 & 3367 \\
2 & C-H alkanes stretching & 2927 & 2927 \\
3 & C=O stretching $(\alpha, \beta-$-unsaturated ketone) & 2856 & 1683 \\
4 & C=C aromatic Bending & 1515 & 1684 \\
5 & C-H alkanes bending & 1464 & 1515 \\
6 & C-O stretching carboxylic acid & 1385 & 1398 \\
7 & C-O in alkoxy stretching & 1291 & 1268 \\
8 & C-H aromatic bending & 1127 & 1127 \\
\hline
\end{tabular}

Altogether, FT-IR results suggested that the force constant of O-H (stretching), and C-O (stretching) functional groups of the phytoconstituents present in the treated ashwagandha root extract were reduced compared with the control sample. Hence, it is assumed that The Trivedi Effect ${ }^{\circledR}$ treatment might be responsible for changing the structural features of the phytoconstituents present in the ashwagandha root powder extract.

\subsection{Ultra Violet-Visible Spectroscopy (UV-Vis) Analysis}

The UV-visible spectra of the control and The Trivedi Effect $^{\circledR}$ treated ashwagandha root extract are shown in Figure 4. The wavelength for the maximum absorbance $\left(\lambda_{\max }\right)$ of the both the control and treated ashwagandha root extract were at 205.4 and $205.6 \mathrm{~nm}$, respectively. There was a minor shift of 
absorbance maxima from the control sample (1.8559) to the treated sample (1.8361). It has been reported that the wavelength for the maximum absorbance for the ashwagandha root extract was at $208.50 \mathrm{~nm}$ [55]. However, no significant change in the $\lambda_{\max }$ of the treated sample was observed compared with the control sample. It is reported that the UV absorbance occurred due to excitation of electrons from highest energy occupied molecular orbital (HOMO) to lowest energy unoccupied molecular orbital (LUMO) [56]. It indicated that energy gap between the HOMO and LUMO in the treated sample was similar compared with the control sample.
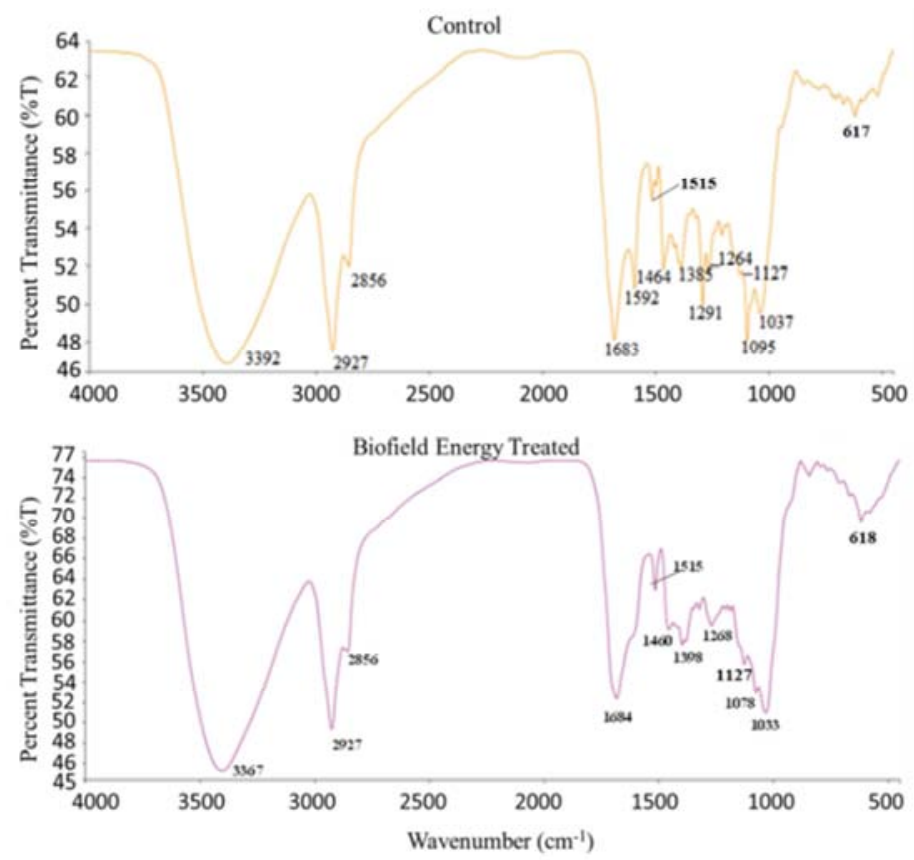

Figure 3. FT-IR spectra of the control and Biofield Energy Treated W. somnifera (ashwagandha) root extract.
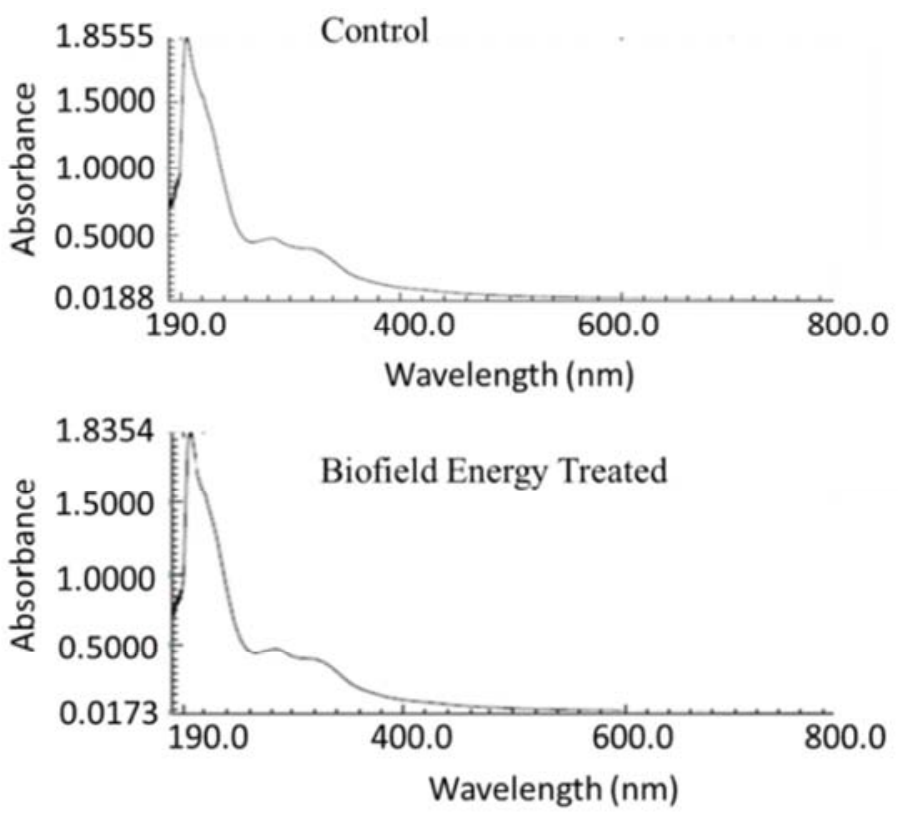

Figure 4. UV-vis spectra of the control and Biofield Energy Treated W. somnifera (ashwagandha) root extract.

Table 3. Thermal degradation steps of the control and Biofield Energy Treated W. somnifera (ashwagandha) root extract.

\begin{tabular}{|c|c|c|c|c|c|}
\hline \multirow{2}{*}{ S. No. } & \multicolumn{2}{|c|}{ Temperature $\left({ }^{\circ} \mathrm{C}\right)$} & \multicolumn{2}{|c|}{$\%$ Weight loss } & \multirow{2}{*}{$\%$ Change $^{a}$} \\
\hline & Control & Treated & Control & Treated & \\
\hline $1^{\text {st }}$ step of degradation & 202.62 & 201.85 & 10.51 & 10.49 & -0.19 \\
\hline $2^{\text {nd }}$ step of degradation & 448.29 & 454.47 & 57.69 & 58.74 & 1.82 \\
\hline $3^{\text {rd }}$ step of degradation & 895.61 & 896.12 & 17.02 & 17.22 & 1.18 \\
\hline
\end{tabular}

a denotes the percentage change in the weight loss of Biofield Energy Treated sample with respect to the control sample. 


\subsection{Thermogravimetric Analysis (TGA)}

The TGA thermograms of both the control and treated samples showed the three steps of thermal degradation (Figure 5) and the results are mentioned in Table 3. The control sample lost weight about $10.51 \%, 57.69 \%$, and $17.02 \%$ in the $1^{\text {st }}, 2^{\text {nd }}$, and $3^{\text {rd }}$ steps of degradation, respectively from its original weight. Similarly, the treated sample lost weight about $10.49 \%, 58.74 \%$, and $17.22 \%$ in the three steps of degradation from its original total weight. The total mass loss in the control and treated sample was $85.22 \%$, and $86.45 \%$, respectively. The total weight loss was increased by $1.44 \%$ in the case of the treated sample compared with the control sample. The current study showed there was a decrease in the thermal stability of the treated ashwagandha compared with the control sample.

\subsection{Differential Scanning Calorimetry (DSC) Analysis}

Measurement of the melting point and latent heat of fusion was performed using DSC analysis (Figure 6. and Table 4). The DSC thermograms of the control and treated samples revealed the sharp endothermic inflection at $96.71{ }^{\circ} \mathrm{C}$ and $91.08^{\circ} \mathrm{C}$ respectively, which was due to the evaporation of the bounded water molecule present in the sample. However, the control and treated ashwagandha indicated the endothermic peak at $203.43^{\circ} \mathrm{C}$ and $201.67^{\circ} \mathrm{C}$, respectively. Several small endothermic peaks also observed in the thermograms of both in the control and treated samples, which may be due to the multiple phytoconstituents present in the ashwagandha root extract in a very small concentration $[57,58]$. The analysis revealed that there was a lowering of the melting point by $0.87 \%$ of the treated sample than the control sample.

Table 4. The melting point $\left({ }^{\circ} \mathrm{C}\right)$ and latent heat of fusion $(\mathrm{J} / \mathrm{G})$ values of the control and Biofield Energy Treated $W$. somnifera (ashwagandha) root extract.

\begin{tabular}{|c|c|c|c|c|}
\hline Sample & $\begin{array}{l}\text { Enthalpy of decomposition } \\
(\Delta \mathrm{H}) \mathrm{J} / \mathrm{g}\end{array}$ & $\begin{array}{l}\text { Onset melting temperature } \\
\left(\mathrm{T}_{\text {onset }}\right)^{\circ} \mathrm{C}\end{array}$ & $\begin{array}{l}\text { Peak melting temperature } \\
\left(\mathrm{T}_{\text {peak }}\right)^{\circ} \mathrm{C}\end{array}$ & $\begin{array}{l}\text { Endset melting } \\
\text { temperature }\left(\mathrm{T}_{\text {endset }}\right){ }^{\circ} \mathrm{C}\end{array}$ \\
\hline Control & 8.66 & 197.97 & 203.45 & 221.37 \\
\hline Trivedi Effect ${ }^{\circledR}$ Treated & 6.77 & 200.23 & 201.67 & 214.13 \\
\hline$\%$ Change $^{\mathrm{a}}$ & -21.82 & 1.14 & -0.87 & -3.27 \\
\hline
\end{tabular}

$\mathrm{T}_{\text {onset }}$ : Onset melting temperature, $\mathrm{T}_{\text {peak }}$ : Peak melting temperature, $\mathrm{T}_{\text {endset }}$ : Endset melting temperature, $\Delta \mathrm{H}$ : Latent heat of fusion, ${ }^{\mathrm{a}}$ denotes the percentage change of Biofield Energy Treated sample with respect to the control sample.
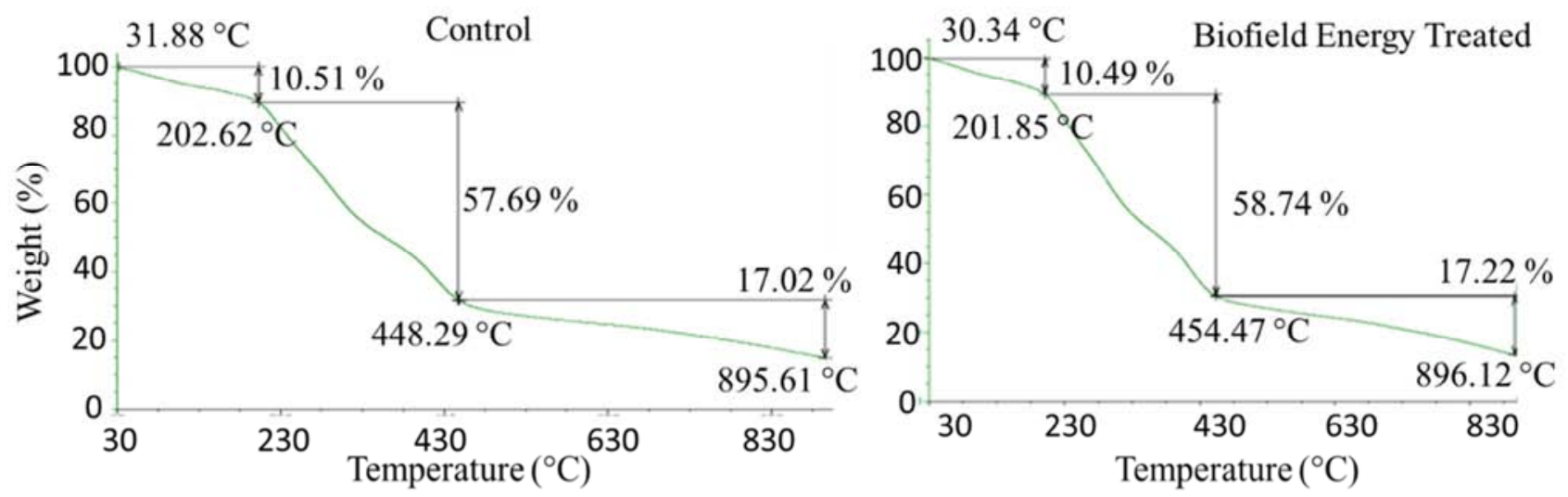

Figure 5. The TGA thermograms of the control and Biofield Energy Treated W. somnifera (ashwagandha) root extract.
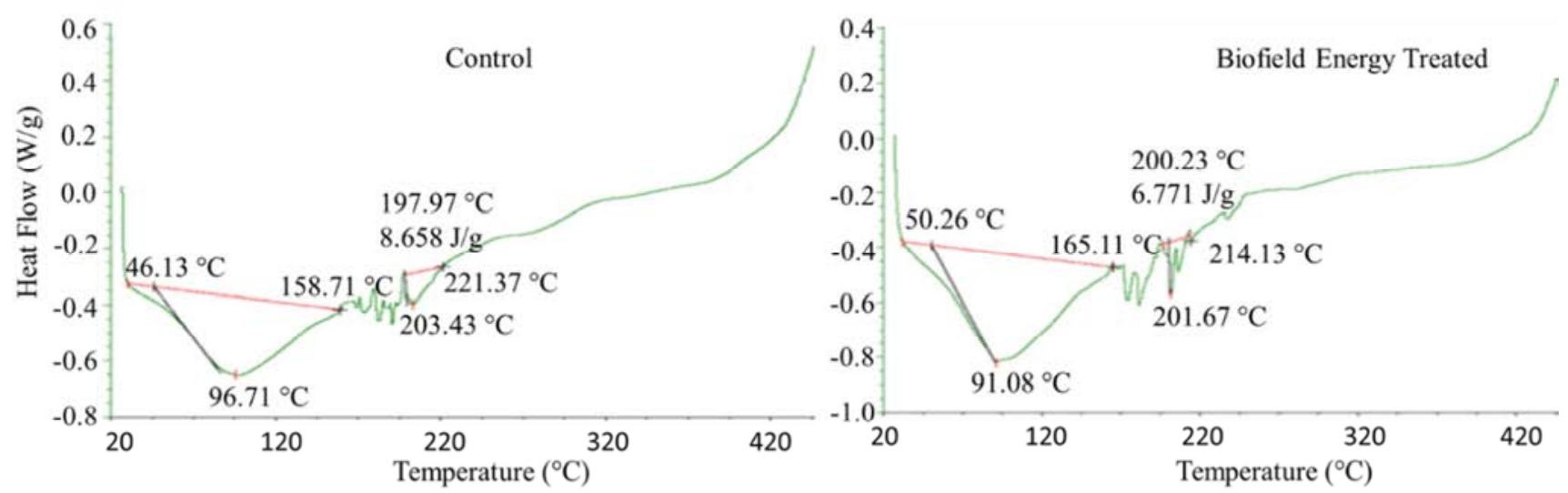

Figure 6. DSC thermograms of the control and Biofield Energy Treated W. somnifera (ashwagandha) root extract. 
The latent heat of fusion $(\Delta \mathrm{H})$ of the treated $(6.77 \mathrm{~J} / \mathrm{g})$ sample was significantly decreased by $21.82 \%$ compared with the control $(8.67 \mathrm{~J} / \mathrm{g})$ sample. The results indicated that the treated ashwagandha needed the less latent heat of fusion compared with the control sample for the process of melting.

It is anticipated from the thermal analysis that The Trivedi Effect $^{\circledR}$ - Energy of Consciousness Healing Treatment might alter the stored potential energy of the ashwagandha root extract which may lead to the reduction in the melting point and latent heat of fusion $(\Delta \mathrm{H})$, which may influence the volatility of the ashwagandha root extract. Since the sample has to be in the vapour phase to be transported, Gas Chromatography is advantageous to thermally volatile compounds $[59,60]$. Hence, the treated sample would be more advantageous in the chromatography point of view for the better metabolite profiling of ashwagandha root extract by the Gas Chromatography-Mass spectroscopy (GC-MS).

\section{Conclusions}

The current research work revealed that The Trivedi Effect $^{\circledR}$ - Energy of Consciousness Healing Treatment (Biofield Energy Healing) Treatment has the outstanding capability for the reduction of the particle size, along with enhanced surface area and altered the thermal properties of $W$. somnifera (ashwagandha) root extract. The PXRD analysis exhibited that both the control and treated samples were amorphous in nature. The particle size at $d_{10}$ and $d_{50}$ values of the treated sample were decreased by $4.66 \%$ and $6.02 \%$ and at $\mathrm{d}_{90}$ slightly increased by $0.99 \%$ compared with the control sample The average surface area of the treated $\left(0.130 \mathrm{~m}^{2} / \mathrm{g}\right)$ sample was increased by $4.84 \%$ compared with the control $\left(0.124 \mathrm{~m}^{2} / \mathrm{g}\right)$ sample. The FT-IR results suggested that the force constant of $\mathrm{O}-\mathrm{H}$ (stretching), and $\mathrm{C}-\mathrm{O}$ (stretching) functional groups of the phytoconstituents present in the treated ashwagandha root extract were reduced compared with the control sample. The UV-vis analysis revealed that the wavelength for the maximum absorbance of the control and treated samples were at 205.4 and $205.6 \mathrm{~nm}$, respectively. The TGA thermograms exhibited three steps of the degradation process, and the total weight loss of the treated $(86.45 \%)$ sample was increased by $1.44 \%$ compared with the control $(85.22 \%)$ sample. The DSC analysis revealed that the melting point of the treated (201.67) sample was reduced by $0.87 \%$ compared with the control $\left(203.43^{\circ} \mathrm{C}\right)$ sample. The latent heat of fusion of the treated $(6.77 \mathrm{~J} / \mathrm{g})$ sample was significantly decreased by $21.82 \%$ compared with the control $(8.67 \mathrm{~J} / \mathrm{g})$ sample. Hence, the treated ashwagandha root extract could be more soluble, absorbable from the gut and more bioavailable compared with the untreated compound and be more suitable for any type of oral pharmaceutical and nutraceutical formulation which might be providing better therapeutic response against various diseases such as diabetes mellitus, allergies and septic shock; stress-related disorders like sleep disorder, insomnia, anxiety, depression, Attention Deficit Disorder (ADD), Attention Deficit Hyperactive Disorder (ADHD), mental restlessness (mind chattering), brain frog, low libido, impotency, lack of motivation, mood swings, fear of the future, confusion, migraines, headaches, forgetfulness, overwhelm, loneliness, worthlessness, indecisiveness, frustration, irritability, chronic fatigue, obsessive/compulsive behavior and panic attacks; inflammatory diseases and immunological disorders like Lupus, Systemic Lupus Erythematosus, Hashimoto Thyroiditis, Type 1. Diabetes, Asthma, Chronic peptic ulcers, Tuberculosis, Hepatitis, Chronic active hepatitis, Celiac Disease (gluten-sensitive enteropathy), Addison Disease, Crohn's disease, Graves' Disease, Pernicious and Aplastic Anemia, Sjogren Syndrome, Irritable Bowel Syndrome (IBS), Multiple Sclerosis, Rheumatoid arthritis, Chronic periodontitis, Ulcerative colitis, Chronic sinusitis, Myasthenia Gravis, Atherosclerosis, Vasculitis, Dermatitis, Diverticulitis, Rheumatoid Arthritis, Reactive Arthritis, Alopecia Areata, Psoriasis, Scleroderma, Fibromyalgia, Chronic Fatigue Syndrome and Vitiligo; aging-related diseases like cardiovascular disease, arthritis, cancer, Alzheimer's disease, dementia, cataracts, osteoporosis, diabetes, hypertension, glaucoma, hearing loss, Parkinson's Disease, Huntington's Disease, Prion Disease, Motor Neurone Disease, Spinocerebellar Ataxia, Spinal muscular atrophy, Amyotrophic lateral sclerosis, Friedreich's Ataxia, Lewy Body Disease, chronic infections and many more.

\section{Abbreviations}

DSC: Differential scanning calorimetry, FT-IR: Fourier transform infrared, $\Delta \mathrm{H}$ : Latent heat of fusion, HOMO: Highest energy occupied molecular orbital, LUMO: Lowest energy unoccupied molecular orbital, PSD: Particle size distribution, $\mathrm{T}_{\text {onset: }}$ Onset melting temperature, $\mathrm{T}_{\text {peak }}$ : Peak melting temperature, $T_{\text {endset }}$ : Endset melting temperature, TGA: Thermogravimetric analysis, UV-vis: Ultra-violet Visible spectroscopy, PXRD: Powder X-ray diffraction

\section{Acknowledgements}

The authors are grateful to GVK Biosciences Pvt. Ltd., Hyderabad, India, Trivedi Science, Trivedi Global, Inc., and Trivedi Master Wellness for their support throughout the work.

\section{References}

[1] Kesarwani K, Gupta R (2013) Bioavailability enhancers of herbal origin: An overview. Asian Pac J Trop Biomed 3: 253266.

[2] Singh N, Bhalla M, Jager P, Gilca M (2011) An overview on ashwagandha: A rasayana (rejuvenator) of ayurveda. Afr J Tradit Complement Altern Med 8: 208-213. 
[3] Alam N, Hossain M, Mottalib MA, Sulaiman SA, Gan SH, Khalil MI (2012) Methanolic extracts of Withania somnifera leaves, fruits and roots possess antioxidant properties and antibacterial activities. BMC Complement Altern Med 12: 175.

[4] Parihar P, Shetty R, Ghafourifar P, Parihar MS (2016) Increase in oxidative stress and mitochondrial impairment in hypothalamus of streptozotocin treated diabetic rat: Antioxidative effect of Withania somnifera. Cell Mol Biol (Noisy-le-grand) 62: 73-83.

[5] Choudhary B, Shetty A, Langade DG (2015) Efficacy of Ashwagandha (Withania somnifera [L.] Dunal) in improving cardiorespiratory endurance in healthy athletic adults. Ayu. 36: $63-68$.

[6] Halder B, Singh S, Thakur SS (2015) Withania somnifera root extract has potent cytotoxic effect against human malignant melanoma cells. PLoS One 10: e0137498.

[7] Verma SK, Kumar A (2011) Therapeutic uses of Withania somnifera (ashwagandha) with a note on withanolides and its pharmacological actions. Asian J Pharm Clin Res 4: 1-4.

[8] Shah N, Singh R, Sarangi U, Saxena N, Chaudhary A, Kaur G, Kaul SC, Wadhwa R (2015) Combinations of Ashwagandha leaf extracts protect brain-derived cells against oxidative stress and induce differentiation. PLoS One 10: e0120554.

[9] Al-Awthan YS, Hezabr SM, Al-Zubairi AM, Al-Hemiri FA (2014) Effects of aqueous extract of Withania somnifera on some liver biochemical and histopathological parameters in male guinea pigs. Pak J Biol Sci 17: 504-510.

[10] Nema R, Jain P, Khare S, Pradhan A, Gupta A, Singh D (2012) Study of Withania somnifera with the spatial reference of phytochemical, FTIR and flavonoids quantification. Int J Pharm Life Sci 3. 1530-1532.

[11] Kumar V, Dey A, Hadimani MB, Marcović T, Emerald M (2015) Chemistry and pharmacology of Withania somnifera: An update. Tang (Humanitas Medicine) 5: e1.

[12] Misra L, Mishra P, Pandey A, Sangwan RS, Sangwan NS, Tuli R (2008) Withanolides from Withania somnifera roots. Phytochemistry 69: 1000-1004.

[13] Lala P, Misra L, Sangwana RS, Tuli R (2006) New withanolides from fresh berries of Withania somnifera $\mathrm{Z}$. Naturforsch 61b: 1143-1147.

[14] Zhao J, Nakamura N, Hattori M, Kuboyama T, Tohda C, Komatsu K (2002) Withanolide derivatives from the roots of Withania somnifera and their neurite outgrowth activities. Chem Pharm Bull 50. 760-765.

[15] Budhiraja RD, Krishan P, Sudhir S (2000) Biological activity of withanolides. J Sci Ind Res 59: 904-911.

[16] Baitharu I, Jain V, Deep SN, Shroff S, Sahu JK, Naik PK, Ilavazhagan G (2014) Withanolide A prevents neurodegeneration by modulating hippocampal glutathione biosynthesis during hypoxia. PLoS One 9. e105311.

[17] Sangwan NS, Sabir F, Mishra S, Bansal S, Sangwan RS (2014) Withanolides from Withania somnifera Dunal: Development of cellular technology and their production. Recent Pat Biotechnol 8: 25-35.

[18] $\mathrm{Ku} \mathrm{SK,} \mathrm{Bae} \mathrm{JS} \mathrm{(2014)} \mathrm{Antiplatelet,} \mathrm{anticoagulant,} \mathrm{and}$ profibrinolytic activities of withaferin A. Vascul Pharmacol 60: $120-126$.
[19] Gao S, Li H, Zhou XQ, You JB, Tu DN, Xia G, Jiang JX, Xin C (2015) Withaferin A attenuates lipopolysaccharide-induced acute lung injury in neonatal rats. Cell Mol Biol (Noisy-legrand) 61: 102-106.

[20] Stenger VJ (1999) Bioenergetic fields. Sci Rev Alternative Med 3.

[21] Rogers, M (1989) "Nursing: A Science of Unitary Human Beings." In J. P. Riehl-Sisca (ed.) Conceptual Models for Nursing Practice. $3^{\text {rd }}$ Edn. Norwark: Appleton \& Lange.

[22] Rubik B (2002) The biofield hypothesis: Its biophysical basis and role in medicine. J Altern Complement Med 8: 703-717.

[23] Nelson LA, Schwartz GE (2005) Human biofield and intention detection: Individual differences. J Altern Complement Med 11: 93-101.

[24] Nemeth L (2008) Energy and biofield therapies in practice. Beginnings. Summer 28. 4-5.

[25] Koithan M (2009) Introducing complementary and alternative therapies. J Nurse Pract 5: 18-20.

[26] Trivedi MK, Patil S, Shettigar H, Mondal SC, Jana S (2015) The potential impact of biofield treatment on human brain tumor cells: A time-lapse video microscopy. J Integr Oncol 4. 141.

[27] Trivedi MK, Branton A, Trivedi D, Shettigar H, Nayak G, Gangwar M, Jana S (2015) Antibiogram typing of biofield treated multidrug resistant strains of Staphylococcus species. American Journal of Life Sciences 3: 369-374.

[28] Trivedi MK, Branton A, Trivedi D, Shettigar H, Nayak G, Mondal SC, Jana S (2015) Antibiogram, biochemical reactions and genotyping characterization of biofield treated Staphylococcus aureus. American Journal of BioScience 3. 212-220.

[29] Trivedi MK, Branton A, Trivedi D, Nayak G, Gangwar M, Jana S (2015) Assessment of antibiogram of biofield energy treated Serratia marcescens. European Journal of Preventive Medicine 3. 201-208.

[30] Trivedi MK, Patil S, Shettigar H, Bairwa K, Jana S (2015) Effect of biofield treatment on phenotypic and genotypic characteristic of Provindencia rettgeri. Mol Biol 4. 129.

[31] Trivedi MK, Branton A, Trivedi D, Nayak G, Gangwar M, Jana S (2015) Bacterial identification using 16S rDNA gene sequencing and antibiogram analysis on biofield treated Pseudomonas fluorescens. Clin Med Biochemistry Open Access 1: 101.

[32] Trivedi MK, Branton A, Trivedi D, Nayak G, Gangwar M, Jana S (2015) Antibiogram, biochemical reactions, and genotypic pattern of biofield treated Pseudomonas aeruginosa. J Trop Dis 4: 181

[33] Trivedi MK, Branton A, Trivedi D, Nayak G, Mondal SC, Jana S (2015) Biochemical differentiation and molecular characterization of biofield treated Vibrio parahaemolyticus. American Journal of Clinical and Experimental Medicine 3. 260-267.

[34] Trivedi MK, Tallapragada RM (2008) A transcendental to changing metal powder characteristics. Metal Powder Report 63: 22-38, 31 . 
[35] Dabhade VV, Tallapragada RMR, Trivedi MK (2009) Effect of external energy on the atomic, crystalline, and powder characteristics of antimony and bismuth powders. Bull Mater Sci 32. 471-479.

[36] Trivedi MK, Patil S, Tallapragada RM (2013) Effect of bio field treatment on the physical and thermal characteristics of vanadium pentoxide powders. J Material Sci Eng S 11: 001.

[37] Trivedi MK, Patil S, Shettigar H, Bairwa K, Jana S (2015) Spectroscopic characterization of chloramphenicol and tetracycline: An impact of biofield. Pharm Anal Acta 6. 395.

[38] Trivedi MK, Patil S, Shettigar H, Bairwa K, Jana S (2015) Spectroscopic characterization of biofield treated metronidazole and tinidazole. Med Chem 5: 340-344.

[39] Trivedi MK, Mohan R, Branton A, Trivedi D, Nayak G, Latiyal O, Jana S (2015) Evaluation of biofield energy treatment on physical and thermal characteristics of selenium powder. Journal of Food and Nutrition Sciences 3: 223-228.

[40] Trivedi MK, Nayak G, Patil S, Tallapragada RM, Jana S, Mishra RK (2015) Bio-field treatment: An effective strategy to improve the quality of beef extract and meat infusion powder. J Nutr Food Sci 5. 389.

[41] Trivedi MK, Branton A, Trivedi D, Nayak G, Singh R, Jana S (2015) Evaluation of physical, thermal and spectroscopic properties of biofield treated $p$-hydroxyacetophenone. Nat Prod Chem Res 3: 190.

[42] Trivedi MK, Branton A, Trivedi D, Nayak G, Panda P, Jana S (2016) Gas chromatography-mass spectrometric analysis of isotopic abundance of ${ }^{13} \mathrm{C},{ }^{2} \mathrm{H}$, and ${ }^{18} \mathrm{O}$ in biofield energy treated $p$-tertiary butylphenol (PTBP). American Journal of Chemical Engineering 4. 78-86.

[43] Trivedi MK, Branton A, Trivedi D, Nayak G, Mishra RK, Jana S (2015) Characterization of physical, thermal and spectral properties of biofield treated 2-aminopyridine. Science Journal of Analytical Chemistry 3: 127-134.

[44] Trivedi MK, Branton A, Trivedi D, Nayak G, Gangwar M, Jana S (2015) Agronomic characteristics, growth analysis, and yield response of biofield treated mustard, cowpea, horse gram, and groundnuts. International Journal of Genetics and Genomics 3: 74-80.

[45] Trivedi MK, Branton A, Trivedi D, Nayak G, Mondal SC, Jana S (2015) Evaluation of plant growth, yield and yield attributes of biofield energy treated mustard (Brassica juncea) and chick pea (Cicer arietinum) Seeds. Agriculture, Forestry and Fisheries 4: 291-295.

[46] Devkar ST, Kandhare AD, Sloley BD, Jagtap SD, Lin J, Tam YK, Katyare SS, Bodhankar SL, Hegde MV (2015) Evaluation of the bioavailability of major withanolides of Withania somnifera using an in vitro absorption model system. J Adv Pharm Technol Res 6: 159-164.
[47] Chereson R (2009) Bioavailability, bioequivalence, and drug selection. In: Makoid CM, Vuchetich PJ, Banakar UV (eds) Basic pharmacokinetics $\left(1^{\text {st }}\right.$ edn) Pharmaceutical Press, London.

[48] Blagden N, de Matas M, Gavan PT, York P (2007) Crystal engineering of active pharmaceutical ingredients to improve solubility and dissolution rates. Adv Drug Deliv Rev 59: 617630 .

[49] Trivedi MK, Mohan TRR (2016) Biofield energy signals, energy transmission and neutrinos. American Journal of Modern Physics 5: 172-176.

[50] Inoue M, Hirasawa I (2013) The relationship between crystal morphology and XRD peak intensity on $\mathrm{CaSO}_{4} \cdot 2 \mathrm{H}_{2} \mathrm{O}$. J Crystal Growth 380: 169-175.

[51] Balzar D, Audebrand N, Daymond MR, Fitch A, Hewat A, Langford JI, Le Bail A, Louër D, Masson O, McCowan CN, Popa NC, Stephens PW, Toby BH (2004) Size-strain linebroadening analysis of the ceria round-robin sample. J Appl Cryst 37: 911-924.

[52] Martin AN, Patrick JS (2006) Martin's physical pharmacy and pharmaceutical sciences: physical chemical and biopharmaceutical principles in the pharmaceutical sciences. Phila: Lippincott Williams and Wilkins. pp. 533-560.

[53] Stuart BH (2004) Infrared spectroscopy: Fundamentals and applications in Analytical Techniques in the Sciences (AnTs). John Wiley \& Sons Ltd., Chichester, UK.

[54] Nie B, Stutzman J, Xie A (2005) A vibrational spectral maker for probing the hydrogen-bonding status of protonated Asp and Glu residues. Biophys J 88: 2833-2847.

[55] Ramachandran A, Kumar MS (2014) FT-IR, UV and antimicrobial activity Withania somnifera and Withania obtusifolia. Int J Pharm Bio Sci 5. B118-B127.

[56] Hesse M, Meier H, Zeeh B (1997) Spectroscopic methods in organic chemistry, Georg Thieme Verlag Stuttgart, New York.

[57] Srivastava A, Alam S, Shahbaaz S, Tiwari M, Mittal A, Chauhan S (2014) Formulation and evaluation of antiacne cream containing Withania somnifera. J Pharm Sci Inv 3: 348352.

[58] Mitra D, Francis S, Varshney L (2004) Calorimetry thermal investigations on $\gamma$ radiation processed natural medicinal products (ashwagandha, amla and hartiki). J Therm Anal Cal 78. 821-829.

[59] McNair H M, Trivedi K M (1992) Gas chromatography and pharmaceutical analyses. ACS Symposium Series 512: 67-84.

[60] Troy DB, Beringer P (2006) Instrumental method of analysis in Remington: The science and practice of pharmacy, $21^{\text {st }}$ Edition, Lippincott Williams \& Wilkins, Philadelphia, USA, pp 633. 